\title{
Smart Traffic Congestion Control
}

\author{
Prof. Ranjeet S. Mote ${ }^{1}$, Dharmesh A. Chhajed ${ }^{2}$, Sambhav V. Dwidmuthe ${ }^{3}$, Komal N. More ${ }^{4}$ \\ Professor, Computer Dept, NBNSSOE, Pune, India ${ }^{1}$ \\ Student, Computer Dept, NBNSSOE, Pune, India ${ }^{2}$
}

\begin{abstract}
Traffic congestion has been one of predominant troubles that most metropolises are going through. It is assumed that identification of congestion is the first step for choosing appropriate mitigation measures. Congestion each in belief and in reality - impacts the motion of people. Traffic congestion wastes time, strength and causes pollution._ere are broadly two factors, which impact the congestion .congestion is 'induced' on the 'micro' stage (e.g. on the road), and 'pushed' on the 'macro' stage. _e micro degree elements are, as an example, many humans want to transport on the same time, too many motors for constrained avenue area. On the opposite facet, macro stage elements are e.g. land-use styles, vehicle possession traits, nearby monetary dynamics, and so on. Street traffic jams preserve to remain a first-rate problem in most cities round the sector, especially in growing regions ensuing in large delays, improved gasoline wastage and financial losses. Because of the poorly planned road networks, a common final results in many developing areas is the presence of small critical areas that are commonplace hot-spots for congestion; bad site traffic management around these hotspots potentially results in elongated visitors jams. in this paper, we first present a easy automatic photo processing mechanism for detecting the congestion tiers in street visitors by processing cctv digital camera photograph feeds. Our algorithm is especially designed for noisy visitors feeds with terrible picture firstclass. Based on stay cctv camera feeds from multiple traffic signals in kenya and brazil, we show evidence of this congestion fall apart behaviour lasting long time-intervals across more than one places.
\end{abstract}

Keywords: traffic congestion, data collection methods, congestion measurement.

\section{INTRODUCTION}

Traffic congestion has been certainly one of major issues that maximum metropolises are facing and hence, many measures have been taken so as to mitigate congestion. It's miles believed that identification of congestion traits is the first step for such efforts because it's miles an vital steering for selecting suitable measures. Congestion - both in perception and in truth - impacts the motion of humans and freight and is deeply tied to the records of high levels of accessibility and mobility.

Traffic congestion wastes time and energy, reasons pollutants and pressure, decreases productivity and imposes costs on society. a commonplace function across street networks in lots of urban areas within the developing international is the presence of essential congestion areas; We confer with a crucial congestion area as one in which a community of roads converge and a big quantity of traffic wishes to traverse the not unusual congestion vicinity.

\section{LITERATURE SURVEY}

[1] Lecture notes in Traffic Engineering and Management by Civil department, IITB.

Transportation is an activity involving the movement of people or goods from one place to another in order to meet the perceived social and economic needs of a user. As these needs change, the transportation system itself evolves and problems occur as it becomes difficult to serve the public interest. One of the negative impacts of any transportation system is traffic congestion.

[2] Robinson, R. "Problems in the urban environment: traffic congestion and its effects." Wollongong Studies in Geography (1984): 14.

Vehicular traffic congestion is a condition that occurs on road networks, which involves the increased queuing of vehicles characterized by increased trip times and fuel consumption. Traffic congestion occurs wherever demand exceeds the capacity of the transportation system and the most common problem is queuing up of vehicles near toll booths

[3] Mittal, Narendra Mohan, and Savita Choudhary. "Comparative Study of Simulators for Vehicular Ad-hoc Networks (VANETs)." International Journal of Emerging Technology and Advanced Engineering Website: www. ijetae.com (ISSN 2250- 2459, ISO 9001: 2008 Certified Journal, Volume 4, Issue 4(2014).

Vehicular traffic can be witnessed mainly on highways and major roads that connect industries. Metropolitan and cosmopolitan cities are found to have higher traffic congestion than other parts. Vehicular traffic congestion poses numerous threats and arises numerous problems to the vehicle drivers. Various industries that bank on freight transport lose a heavy sum of money annually due to 
Vol. 6, Issue 1, January 2017

traffic congestion. Various institutions, government bodies and organizations have undertaken surveys and studies to understand the causes and consequences of vehicular traffic congestion and also to provide efficient solutions to avoid traffic congestion. VANET also helps us to achieve car to car communications and perform simulations at a relatively low cost.

[4] Zeadally, Sherali, Ray Hunt, Yuh-Shyan Chen, Angela Irwin, and Aamir Hassan. "Vehicular ad hoc networks (VANETS): status, results, and challenges." Telecommunication Systems 50, no. 4 (2012): 217-241.

Recent efforts have placed a strong emphasis on VANET design implementations.

\section{SYSTEM ANALYSIS}

Measures aimed at lowering congestion may be either call for or supply aspect oriented. It is consequently crucial to distinguish both sorts of measures. Three primary factors have an impact on the supply side of avenue travel. Firstly, capability is one of the most critical elements of avenue space deliver. For example, the overall kilometers of roads and the number of lanes decide the potential of the street network. Secondly, the operation of the street network influences supply. Maximizing the efficiency of operations, including optimizing signals improves "supply". Thirdly, the supply of the street shipping equation is likewise attracted through incidents including accidents or street works. Importantly, the remaining components can be influenced by means of visitors control strategies. It is as a result the supply-aspect of the road network that may be optimized through traffic control tools. Deliver of street space is especially decided by using past investment decisions and modern-day operations. Modifications within the supply aspect of road space hence contain construction of recent street area or discounts in present avenue space. Adjustments in traffic operations are additionally considered to be supply aspect measures. Demand for road area is influenced via a massive number of problems.

Basically, demand is created when the need for travel among beginning and a vacation spot arises. Demand therefore strongly relies upon on socio-monetary and populace elements. Every other crucial issue influencing demand is the relative cost of avenue journey as well because the availability of alternative way of delivery. Other elements that affect call for avenue journey are availability of parking and the social notion of car versus public transport tour. This paper discuss the existing practices in specific nations, the contributions by means of people and prevailing methodologies for measurement of the congestion at the side of the important assessment of the methods. Review has additionally been accomplished on the subject of Indian situations. The critique and the advised technique may be beneficial for comparable developing nations.

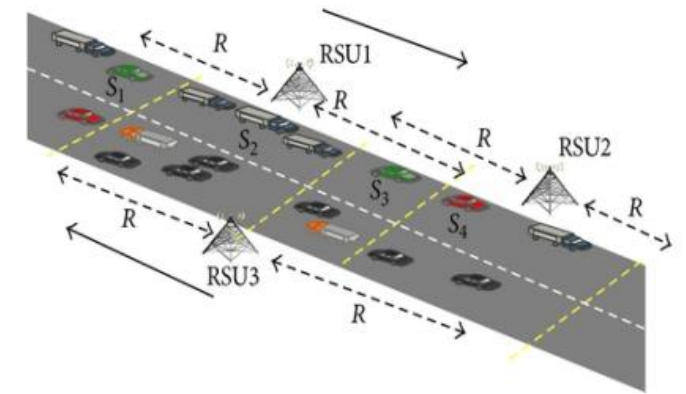

\section{PROPOSED SYSTEM}

Vanet is most important and new type ad-hoc networking which needs attention. If research of scholars and technology of automobile industry combine work in this area they can reduces accidents happening on roads. Basically Vanet is Ad-hoc network in which vehicles are treated as Node. And these nodes are communicating with each other as well as RSU [Road side unit]s on the road. In our proposed system we taking care for traffic arise on road or highways so if congestion occurs at any rout then we will give the information to the other vehicle which are go running on the same track. This is done by using Road side units on the road and GPS tracking system of the particular vehicle.

At any condition if the traffic is more on road and at the same time various vehicles are coming on same rout then we handle that condition by using the RSU. In proposed research work first we create a VANET machine which will keep the an intersection for every turning points it'll maintain each node vicinity that is arrive in that area.

Traffic congestion is calculated via considering the region of the car and the variety of automobiles in a selected location boundary. If a vehicle is found to transmit the equal area records for a prolonged period of time, then the car is marked for traffic boundary. A traffic boundary is computed with the marked car's area. The quantity of cars within that boundary is envisioned. Every of those motors is checked for region to perceive the density of traffic. The congestion statistics offers information about the lifestyles of congestion in a selected place.

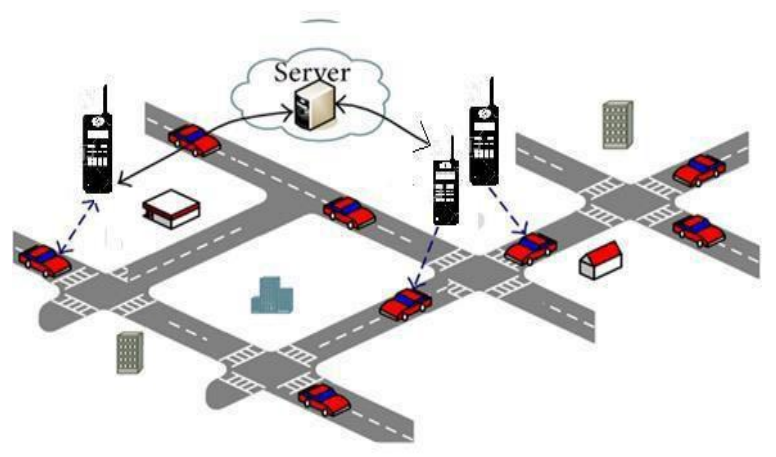

Fig:- Architecture diagram 


\section{CONCLUSION}

The vehicular visitor's records may be monitored periodically to identify the height hours of the day. All through height hours, the roads can be studied for visitors. A class of site visitors congested roads and site visitors much less roads can be obtained. Additionally, the change routes for traffic congested routes cautioned by means of RSU's can be used to direct site visitors float in all viable routes equally. This manner, all of the roads are used equally and thereby reduce congestion.

\section{REFERENCES}

[1] Lecture notes in Traffic Engineering and Management by Civil department, IITB

[2] Robinson, R. "Problems in the urban environment: traffic congestion and its effects." Wollongong Studies in Geography (1984):14.

[3] Mittal, Narendra Mohan, and Savita Choudhary."Comparative Study of Simulators for Vehicular Ad-hoc Networks (VANETs)." International Journal of Emerging Technology and Advanced Engineering Website: www. ijetae. com (ISSN 2250-2459, ISO 9001: 2008 Certified Journal, Volume 4,Issue 4 (2014).

[4] Zeadally, Sherali, Ray Hunt, Yuh-Shyan Chen, Angela Irwin, and Aamir Hassan. "Vehicular adhoc networks (VANETS): status, results, and challenges." Telecommunication Systems 50, no. 4(2012): 217-241.

[5] El-Sersy, Heba, and Ayman El-Sayed. "Survey of Traffic Congestion Detection using VANET."

[6] Zeadally, S., Hunt, R., Chen, Y. S., Irwin, A., \&Hassan, A. (2012). Vehicular ad hoc networks (VANETS): status, results, and challenges. Telecommunication Systems, 50(4), 217-241. 